\title{
AS CONTRARREFORMAS DO ENSINO SUPERIOR E A LUTA PELA EDUCAÇÃO DE QUALIDADE
}

\section{THE COUNTER REFORMS IN HIGHER EDUCATION AND THE FIGHT FOR A}

\author{
QUALITY EDUCATION
}

Maria Beatriz Costa Abramides ${ }^{1}$

\section{RESUMO}

Este artigo trata das contrarreformas do Ensino Superior no Brasil sob a lógica neoliberal nos governos Fernando Henrique Cardoso (FHC), Luiz Inácio Lula da Silva (Lula) e Dilma Vana Rousseff. Essas orientações norteadas pela macroeconomia internacional colocam para o movimento da educação novos desafios na luta pelo ensino público, laico, gratuito, universal e de qualidade. A precarização do ensino superior atinge todos os cursos, analiso nesse contexto o alcance na formação do assistente social e a resposta dos docentes e estudantes na luta pelo ensino de qualidade.

PALAVRAS CHAVE: Contrarreforma. Movimento da Educação. Serviço Social. Formação.

\begin{abstract}
This article is about the counter reforms in higher education under neoliberal logical in Fernando Henrique Cardoso (FHC), Luiz Inácio Lula da Silva (Lula) and Dilma Vana Rousseff governance. This rules oriented by the International macro economy introduces to the education movement new challenges to fight for a public, lay, gratuitous, universal, quality education. The dissolution of higher education enlace all courses, the investigation analysis the reach of Social Work formation and the professor and students answers to fight for a quality education.
\end{abstract}

KEYWORDS: Counter Reforms. Education Movement. Social Work. Formation.

\section{INTRODUÇÃO}

A luta pelo ensino público, laico, universal, de qualidade, presencial, de acesso e permanência a todos é uma luta histórica da classe trabalhadora no Brasil. Nesse trabalho estabeleço os elementos centrais da contrarreforma do ensino superior, no Governo de Fernando Henrique Cardoso, em 1994, momento em que se consolida o neoliberalismo no Brasil, se expande e se aprofunda na contrarreforma do Governo

\footnotetext{
${ }^{1}$ Professora doutora, do Curso de Serviço Social da Faculdade de Ciências Sociais da PUCSPGraduação e Pós-Graduação. Telefone 11 38681696, e-mail: biabramides@gmail.com. Serv. Soc. \& Saúde, Campinas, SP v. 11, n. 1 (13), p. 7-26 jan./ jun. 2012 ISSN 1676-6806
} 
Lula, de 2002 a 2010, e apresenta sua continuidade no Governo de Dilma Vana Rousseff, a partir de 2011. Busco compreender seus rebatimentos na precarização e mercantilização do ensino e destacar as lutas pela educação no Ensino Superior e suas implicações na particularidade da formação profissional dos assistentes sociais.

A categoria dos assistentes sociais que rompe com o conservadorismo da profissão, em 1979, apresenta no III Congresso Brasileiro de Assistentes Sociais (CBAS), seu marco público e coletivo, no histórico "Congresso da Virada". O faz em um momento de ascenso da luta de classes no país, que se espraia no final dos anos 70 e na década de 80. A condição de assalariamento dos profissionais assistentes sociais inseridos na divisão sócio técnica do trabalho, os identifica como trabalhadores e com os trabalhadores. Colados sindicalmente às lutas sociais no interior do sindicalismo classista e das lutas populares, se inserem na luta pelo ensino público de qualidade e participam da luta mais geral da classe trabalhadora contra a ditadura, anti-imperialista, anticapitalista, socialista na direção do projeto de emancipação humana.

Com a crise estrutural do capital no plano internacional, a partir de 73, o capitalismo estabelece novas estratégias para recuperar suas taxas de lucro, na esfera do mundo do trabalho, na esfera do Estado e da cultura com fortes ataques à classe trabalhadora. No mundo do trabalho se expande o desemprego estrutural, há uma redução dos postos de trabalhos; flexibilização das relações de trabalho, com trabalho temporário, parcial, por projeto, sem carteira-assinada, ampliando significativamente o trabalho informal. Na esfera do Estado verifica-se a avalanche das privatizações, a redução de recursos orçamentários para os serviços sociais, a desresponsabilização do Estado que se torna "mínimo" para os trabalhadores e "máximo" para o capital; imprimem-se as Contrarreformas do Estado, Sindical, Trabalhista, Previdenciária, do Ensino Superior, com a destruição de direitos sociais e trabalhistas em uma lógica privatista e mercantil para atender aos interesses do grande capital. Na esfera da cultura alardeia-se a chamada "pós-modernidade" pela ideologia do fim da história, do triunfo do capitalismo e sua inexorabilidade, na negação das teorias estruturantes, da ideia da imediaticidade, em que tudo é efêmero, fugaz, aparente, com grande ênfase no indivíduo, na competitividade, na negação da existência das classes sociais e de seus antagonismos, na negação do protagonismo proletário no processo emancipatório, na ideologia do consenso, da colaboração entre as classes, negando o trabalho como categoria universal e fundante do ser social. 
A categoria organizada dos assistentes sociais em seus fóruns da formação, do exercício profissional e estudantil vem se posicionando claramente contra os ataques aos trabalhadores nas esferas do mundo do trabalho, do Estado e da cultura. Essa lógica societal destrutiva do capitalismo se instaura como resposta à sua crise estrutural internacional em 1973, eclode em 2007 e se aprofunda em 2011.

É o capital fetiche, de internacionalização e financeirização da economia que se aprimora para recuperar as taxas de lucro, na crise de superprodução, pelas formas de superexploração do trabalho para extração de mais-valia relativa e absoluta, que se ampliam drasticamente. A fase atual do capitalismo se caracteriza pelo esgotamento do chamado "Estado de Bem-Estar Social ", que vigorou no epicentro do capitalismo, de 1945 a 1973, no período das ondas expansivas do crescimento econômico. O capitalismo, ao entrar em sua crise estrutural, apresenta um quadro de contradição antagônica entre as forças produtivas e as relações sociais de produção, que exaurem qualquer possibilidade progressiva, posto que se encontra em decomposição (MARX), o que não significa dizer que não tenha fôlego para dar continuidade a seu processo de exploração e de dominação de forma internacionalizada e imperialista. A este período do desenvolvimento capitalista Marx anunciara a possibilidade histórica de um tempo de revolução social. Para tanto seriam necessárias condições objetivas, as que estão postas (contradição antagônica entre forças produtivas e relações sociais de produção) e subjetivas, essas últimas dadas pelo grau de consciência e organização da classe, o que apresenta na conjuntura atual questões fundantes como: a ilusão politicista das massas em governos que se conformaram a partir da luta dos trabalhadores e que são a representação do capital na esfera da política, enquanto classe dirigente; a regressão de setores combativos do movimento sindical e popular que se construíram de forma ofensiva e classista e que hoje são estadistas, governistas; a necessidade de partidos classistas revolucionários na perspectiva da supressão positiva da ordem do capital, o que recoloca para os militantes da esquerda revolucionária a perspectiva tática e estratégica de unidade na luta e constituição de frentes únicas classistas que avancem na luta da ação direta.

Neste texto me dedicarei ao tema da luta pela educação. Sabemos que a escola sem classes somente se concretizará em uma sociedade sem classes, porém as lutas imediatas pela educação devem estar articuladas à luta pelo socialismo na perspectiva estratégica do projeto de emancipação humana, pelo fim da propriedade privada dos 
meios de produção, o fim das classes sociais, o fim do Estado, o fim da exploração e de todo tipo de opressão social de raça, etnia, gênero, orientação sexual, na supressão positiva da ordem do capital em uma sociedade da auto-organização dos indivíduos sociais livremente associados. Esse é o horizonte histórico estratégico para os trabalhadores a qual o nosso Projeto Ético-Político Profissional se articula.

As lutas imediatas pelo ensino laico, público, universal, gratuito, de qualidade, se relacionam aos aspectos da realidade sociohistórica conjuntural de precarização do Ensino Superior e de seus rebatimentos na formação e exercício profissional dos assistentes sociais em suas particularidades. Isso pressupõe identificar os elementos das contrarreformas do Ensino Superior no Brasil, de 1994 a 2012, cujos pontos estruturantes se reafirmam no Plano Nacional da Educação, para o decênio 2010-2020.

\section{A contrarreforma do Ensino Superior no Governo de FHC}

A contrarreforma do Ensino Superior implantada no governo de FHC se implanta sob a lógica gerencial da contrarreforma do Estado desenvolvida por Bresser Pereira, ministro da Administração e Reforma do Estado. O objetivo dessa contrarreforma foi o de transformar a natureza da universidade, de instituição social para organização social (OS), regendo-se por medidas provisórias e emendas constitucionais, submetendo-a aos interesses privados empresariais.

A instituição social aspira à universalidade, tem a sociedade como
referência normativa e valorativa, se percebe na divisão social e
política e busca universalidade para responder às contradições sociais
e políticas, inseparável das ideias de formação, criação e reflexão
crítica e, portanto, da ideia de democratização do saber e da
democracia, bem como não pode furtar-se afirmativa ou
negativamente ao ideal socialista [...] a organização social tem a si
própria como referência, apresenta uma instrumentalidade voltada
para ideias de eficácia e sucesso no emprego não questiona sua
existência, seu lugar na luta de classes, se configurando em
universidade funcional e gerencial (CHAUí, 1999, p. 4).

A universidade funcional se volta para a formação rápida de profissionais que passam a ser requisitados como força de trabalho qualificada e barata, por meio de baixos salários. No processo de formação profissional a modificação e adequação de conteúdos e programas segue a lógica do mercado em direção oposta ao sentido clássico de uma universidade voltada ao conhecimento e à formação acadêmica e profissional. Substitui-se o currículo mínimo por diretrizes curriculares, o que desconfigura a solidez teórica no processo formativo. 
A universidade operacional se caracteriza por ser flexível, de estímulo à produtividade e resultados quantitativos. A docência é compreendida por mera transmissão rápida de conhecimentos e regulada por contrato de gestão, de avaliação externa por índices de produtividade, de incentivo a competição em detrimento de processos autônomos de avaliação definidos pela universidade.

A contrarreforma do Ensino Superior se apoia fundamentalmente na Lei de Diretrizes e Bases 9394/96 (LDB), e seu estatuto de legalidade que imprime:

[...] a flexibilização enquanto sua grande estratégia de enraizamento, fortalecimento e expansão da "universidade operacional e gerencial", de destruição da universidade fundada no reconhecimento público de legitimidade que lhe confere autonomia do saber em relação à religião e ao Estado (CHAUÍ, 1999, p. 4).

[...] o favorecimento da expansão do privatismo, a liquidação da relação ensino, pesquisa e extensão, a supressão do caráter universalista, a subordinação dos objetivos universitários às demandas do mercado, a redução do grau de autonomia pensada apenas como autonomia financeira; nexo organizador da vida universitária; a supressão da vida universitária são os traços fundamentais que resultam, como um pacto para o ensino superior, desse duplo e imbricado movimento político de ajuste e de reforma do Estado [...]. Não se trata de acabar com a universidade brasileira, trata-se de acabar com o sistema universitário público (NETTO, 2000, p. 29).

A concepção gerencial da contrarreforma do Estado e o projeto de educação previsto na LDB seguem a lógica capitalista da relação custo-benefício em seus dois objetivos centrais: o primeiro, de natureza ideológica, ao transformar as instituições sociais em organizações sociais (CHAUÍ, 1999); o segundo pela "transferência de todos os centros intermediários de decisão para a área de influência do grande capital” (NETTO, 2000, p. 24).

A Política do Ensino Superior no Brasil, por meio da universidade operacional, desenvolve uma racionalidade instrumental, constitutiva do ideário neoliberal, de sucateamento e destruição do ensino público, com redução de recursos da dotação orçamentária para a educação, ausência e ou redução de concursos públicos e de subordinação do ensino às demandas do mercado.

É alarmante a expansão do ensino privado no país, que no ano 2000 conta com 78,52\% das instituições de nível superior, simultaneamente ao aniquilamento do ensino público que fora parte da conquista democrática.

No governo de FHC, de 1995 a 2002, o número de alunos na rede privada cresceu em $86 \%$, e na rede pública a taxa foi de apenas $28 \%$. A diferença entre o Serv. Soc. \& Saúde, Campinas, SP v. 11, n. 1 (13), p. 7-26 jan./ jun. 2012 ISSN 1676-6806 
crescimento do número de alunos fez com que a rede privada, em 2002, contasse com 1.442 escolas de nível superior, enquanto a rede pública contava com 195 escolas.

A lógica é a de expansão e de substituição das instituições sociais por organizações sociais (OSs), definidas como "instituições de direito privado e de interesse público”. A Reforma do Estado do governo FHC cria as fundações de caráter privado no interior das universidades públicas e estabelece os Projetos de Parceria Público-Privada (as PPPs) para a pesquisa, cujo interesse é determinado pelas exigências empresariais em direção oposta às das necessidades sociais presentes na realidade. Esse processo sela a desresponsabilização do Estado com a Educação e com o conjunto das políticas sociais públicas.

A “universidade operacional” se volta para uma rápida e aligeirada formação profissional dirigida às exigências do mercado de trabalho. São criados os cursos sequenciais de curta duração de nível superior não graduado para os alunos de ensino médio, seguindo as metas do Banco Mundial, de expansão numérica dos alunos no Ensino Superior, independentemente da formação de qualidade. A universidade operacional necessita ser produtiva e flexível sendo regulada por contratos de gestão, com o desaparecimento e a diminuição da docência, do ensino presencial, marca essencial da formação acadêmica universitária.

As inovações propostas pela LDB se explicitam por meio de: cursos sequenciais, exame nacional de curso, avaliações meramente quantitativas, graduação a distância, mestrado profissionalizante, com o objetivo de elevar de $11 \%$ a $30 \%$ o número de universitários na faixa etária entre 18 e 24 anos, o que implica em uma massificação dos cursos aos setores mais pauperizados em detrimento de ampliação de curso públicos nas universidades públicas, democratizando o acesso e a permanência aos trabalhadores e seus filhos.

Essa lógica de expansão acelerada do ensino superior, conforme afirma o Plano Nacional de Educação (PNE), é estabelecida pelas metas dos organismos multilaterais, como o Banco Mundial (BIRD) e Banco Interamericano de Desenvolvimento (BID) em consonância com o Fundo Monetário Internacional (FMI), para os países sob dependência e subordinação ao capital internacional, no qual a lógica mercantil e privada impera em detrimento da qualidade formativa.

Novos cursos, cursos sequenciais, tele ensino, ensino a distância se firmam no sentido de ajustar os cursos às necessidades do mercado. Gastar menos com educação, conceder um diploma em menor tempo e a consequente precarização do trabalho com Serv. Soc. \& Saúde, Campinas, SP v. 11, n. 1 (13), p. 7-26 jan./ jun. 2012 ISSN 1676-6806 
menores salários sustentam a determinação do ensino como negócio, facilitando a intervenção do grande capital privado.

A Reforma do Ensino Superior do Governo FHC de forte marca economicista e privatista retira a educação da esfera dos direitos e a coloca como um serviço disponível no mercado. A educação sai da esfera do público e volta-se para a esfera do privado. Ao sair do âmbito dos direitos, legalmente pela reforma do Estado, entra para a esfera dos serviços não exclusivos do Estado, assim como ocorre com a Saúde e a Previdência Social.

A LDB, ao corroer e destruir o ensino público, laico, gratuito, universal e presencial, introduz: “a flexibilização, a qualidade e a avaliação”. Os parâmetros estabelecidos se explicitam por meio de:

a. "Flexibilização" que significa eliminar o regime único de trabalho, adaptar os currículos da graduação e da pós-graduação às demandas impostas pelo mercado, separar docência da pesquisa, vincular e subordinar a pesquisa e a extensão à política de mercado e não às necessidades da realidade social;

b. "Qualidade” que pressupõe atender as necessidades da modernização econômica do desenvolvimento capitalista com padrões de produtividade, não importando o que, o como e para que se produz, sob a lógica racional instrumental de resultados;

c. “Avaliação" pela quebra da autonomia universitária por meio do "provão" ranqueado no Governo FHC e ENADE, nos governos Lula e Dilma aos estudantes e avaliação institucional e de curso meritocrática e externa; quebra do princípio constitucional da gratuidade do ensino pelo ensino privado nos cursos de extensão e muitos pós nas universidades públicas; quebra da autonomia na produção do conhecimento e de negação da teoria por intermédio de um conhecimento meramente instrumental.

\section{A contrarreforma do Ensino Superior no governo Lula da Silva e sua continuidade no Governo Dilma Vana Rousseff}

O Governo Lula apresentou um conjunto de contrarreformas: previdenciária e tributária (2003), sindical e do ensino superior (2004 e 2005) e a trabalhista que, a princípio, seria em 2006, foi adiada, e novamente anunciada no governo Dilma Rousseff, em 2012. As contrarreformas seguiram o leito de continuidade e Serv. Soc. \& Saúde, Campinas, SP v. 11, n. 1 (13), p. 7-26 jan./ jun. 2012 ISSN 1676-6806 
aprofundamento do pacto neoliberal de manter o superávit primário, transferindo 4,25\% do PIB, sob a forma de juros para pagar os títulos da dívida pública, cujo montante foi calculado em 60 bilhões de reais para o ano de 2004, que ainda permanece em 2012.

As consequências da subordinação da política macroeconômica fiscal e de juros à imposição do FMI e dos organismos multilaterais recaem sobre as massas trabalhadoras pelo índice de 20\% de desemprego nos grandes centros urbanos, atingindo 40\% dos jovens de até 24 anos. Essa política econômica ortodoxa se opõe às prioridades sociais e trabalhistas de distribuição de renda e de riqueza, de retomada do setor produtivo, da implantação de uma política agrícola e de reforma agrária e urbana, postuladas no programa de campanha eleitoral. Lula justificou a adoção dessa política de proteção aos credores por ter recebido um orçamento comprometido para o ano de 2003, utilizando-se da expressão “herança maldita” do Governo de FHC. Porém essa linha teve sua continuidade no segundo mandato, até o final de 2010, e permaneceu no governo atual de Dilma Rousseff.

Ao se analisar a Lei de Diretrizes Orçamentárias (LDO), confirma-se a continuidade de restrição do orçamento para as áreas sociais, substituindo-se por programas compensatórios, “enfeitada com uma política tipo Fome Zero” (OLIVEIRA, 2003, p. 40), como parte do pacto financeiro e social desenvolvido sob orientação marcadamente assistencialista. Os programas sociais assistenciais se desvinculam de políticas sociais estruturantes como política de emprego, e outras políticas sociais, com saúde e educação que se encontram reduzidas pela quebra de direitos e em grande medida privatizadas. Torna-se evidente o apelo moral à solidariedade indiferenciada, a qual se contrapõe à solidariedade de classe como valor estabelecido historicamente pelos trabalhadores.

Por outro lado, o governo Lula em seus dois mandatos, de 2002 a 2010, seguido pelo governo Dilma a partir de 2011, estabeleceram a manutenção a Lei de Responsabilidade Fiscal (LRF), que limita a aplicação do orçamento público nos estados e municípios, para cumprir os acordos do pagamento dos juros dos serviços da dívida externa de proteção aos credores internacionais. É lamentável e inadmissível um país da dimensão continental, o Brasil, ter somente 9\% dos jovens de 18 a 24 anos nas universidades, e, no ciclo expansionista do Governo Lula, que atinge 12\%, o faz nos cursos aligeirados de ensino a distância, por meio do Pró-Uni, transferindo recurso público para a esfera privada, e pelo Reuni, um programa de ensino na esfera pública superior, de formação precarizada. A Argentina, país vizinho, que tem o ensino público, Serv. Soc. \& Saúde, Campinas, SP v. 11, n. 1 (13), p. 7-26 jan./ jun. 2012 ISSN 1676-6806 
gratuito, para todos, fruto das lutas da educação, apresenta um índice de $40 \%$ de jovens na mesma faixa etária cursando o ensino superior, público, gratuito, universal, sem o filtro de vestibular.

O orçamento para o ensino superior definido pelo governo de Lula da Silva representou a pequena quantia de 4,3\% do PIB, semelhante à irrisória quantia estabelecida pelo governo FHC. Ressalto que esse índice não corresponde sequer aos 7\% anunciados no programa eleitoral, o qual previa ainda a derrubada dos vetos de FHC ao Plano Nacional da Educação configurado na Lei 10172, que estabelece a destinação de um montante de $10 \%$ do PIB para a educação nos próximos anos e o Governo Dilma mantém o irrisório índice de 5\% para a educação.

A fração do PIB voltada para a educação no governo Lula e no Governo Dilma está em desacordo à proposta de destinação imediata de $10 \%$ do PIB para a Educação por deliberação do Congresso Nacional de Educação (II CONED), realizado em Belo Horizonte em novembro de 1997. O comprometimento de 10\% do PIB, porém, é para o pagamento dos serviços da dívida, em uma redução de 13,4\% do orçamento federal previsto para a educação.

A principal medida a ser considerada em relação às Instituições de Ensino Superior Público e Privado (IES) refere-se à compra pelo Governo de 20\% a 25\% das vagas ociosas das universidades privadas, por meio do "Programa Universidade Para Todos” (PROUNI), para alunos vindos das escolas públicas, incluindo negros e índios, “sob a máscara de auxílio aos alunos pobres das escolas públicas” (OLIVEIRA, 2004, p. 33) cuja medida é implantada no Governo Lula com continuidade no Governo Dilma. Estabelece o pagamento de mensalidades dos alunos em escolas privadas, quando esse recurso deveria ser destinado ao ensino público estatal, ampliando-o em relação ao acesso e à permanência dos estudantes despossuídos e pauperizados desse país, os filhos da classe trabalhadora. O Banco Mundial reafirma as reformas neoliberais para educação: a competitividade e o crescimento econômico do país dependem de investimentos em educação, em capital humano [...]. Ressalva, porém, de que face à necessidade de manter o ajuste fiscal, o país não deve aumentar os gastos no setor, "mas distribuir melhor os recursos existentes" [...] em que "o modelo predominante de ensino público superior nos países em desenvolvimento beneficia, principalmente, as famílias de maiores recursos"[...] Os filhos dessas famílias estão fortemente subvencionados pelo 
restante da sociedade para frequentar as universidades públicas (OLIVEIRA, 2004, p. 32).

O governo propõe ainda que as universidades públicas recorram a recursos “extragovernamentais”, portanto privados, o que vem ocorrendo com a presença de fundações privadas nas universidades públicas, em cursos de especialização, pósgraduação e pesquisa demandada pelo interesse privado. Foram repassados 400 milhões de reais para as entidades filantrópicas na esfera privada, cujo investimento o governo declarou não ter como fiscalizar. A partir daí o governo lança a proposta de favorecimento do ensino privado e mercantil em detrimento do ensino público. A grande maioria das escolas privadas se concentra apenas em atividade do ensino, desobrigando-se da pesquisa e da extensão. Em 2012, cerca de 85\% das Unidades de Ensino Superior se concentram na esfera privada; dentre essas, 82\% são filantrópicas privadas mercantis, e $13 \%$ são as chamadas comunitárias em que uma parcela expressiva aderiu ao ensino em uma perspectiva mercantil.

Cabe, portanto, às universidades privadas comunitárias que historicamente cumpriram sua função social resistir ao neoliberalismo, reabrindo o debate em defesa da luta pela estatização, (como, por exemplo, a PUC-SP e outras PUCs), colocando seu acúmulo teórico-intelectual a serviço do ensino público, gratuito, universal e presencial.

O ordenamento neoliberal prevê, os projetos de “parcerias público-privadas”, de focalização em programas compensatórios à população mais pobre como se a essa não pudesse estar voltado o acesso e permanência ao ensino público de qualidade. As desigualdades sociais, econômicas, políticas e culturais se ampliam ascendentemente na sociedade de classes. Torna-se oportuno dizer: se o governo não enfrentar o problema de emprego para a juventude, não enfrentará a questão da permanência dos alunos no ensino.

A autonomia universitária se encontra atrelada ao financiamento que permite estabelecer contratos de gestão no "Pacto de Educação para o Desenvolvimento Inclusivo" com a expansão da educação a distância como estratégia para superar a educação presencial, o que envolve uma formação meramente numérica, massificada em detrimento da qualidade. A docência é descaracterizada como cerne do ensino universitário, e o ensino virtual se sobrepõe à formação, em resposta à lógica do mercado segundo as orientações internacionais. Aprofunda-se a precarização do ensino e do trabalho, pelo aumento de carga didática dos professores e do número excessivo de estudantes por sala de aula. O gerenciamento privado sustenta-se sob o argumento de Serv. Soc. \& Saúde, Campinas, SP v. 11, n. 1 (13), p. 7-26 jan./ jun. 2012 ISSN 1676-6806 
que esse é mais eficiente do que o da gestão pública, o que justifica a continuidade da existência de fundações nas instituições públicas.

A contrarreforma do ensino do governo Lula propôs a criação de conselhos nas universidades, de controle externo formados por representantes da decantada sociedade civil, que, na verdade, se resumem aos empresários da educação, ao governo e à burocracia sindical, numa clara quebra da autonomia e democracia universitárias.

A autonomia universitária pressupõe a necessidade de avançar na gestão por aqueles que nela trabalham e estudam: professores, funcionários e estudantes. A avaliação educacional deve se constituir em uma cultura permanente nas universidades, como um processo formativo pedagógico a ser definido no interior das universidades e envolver professores, funcionários e estudantes, a partir das reais necessidades e compromissos sociais, e não as impostas pelo capital, que exige redução de recursos orçamentários para a educação pública e favorecimento do ensino privado.

\section{Contrarreforma no Ensino Superior: implicações para o Serviço Social, desafios e lutas necessárias}

Selada a partir do governo FHC e, permanecendo em vigor nos Governos Lula da Silva e Dilma Rousseff, a contrarreforma no Ensino Superior atinge o conjunto dos cursos do país em seus elementos centrais: expansão do ensino privado, liquidação da relação ensino, pesquisa e extensão, supressão do caráter universal, subordinação dos objetivos acadêmicos à lógica do mercado, redução da autonomia universitária, cursos rápidos e aligeirados a distância e semipresenciais de acordo com os ditames dos organismos internacionais, precarização das condições de ensino e trabalho. As medidas dessa reforma têm na LDB seu suporte institucional. Novas modalidades de cursos ampliam a subordinação da universidade aos interesses do capital, entre eles os cursos sequenciais, a educação a distância e os mestrados profissionalizantes, que se caracterizam por cursos que priorizam a quantidade em detrimento da qualidade, o aligeiramento dos cursos e sua adequação às exigências do mercado, ou seja, a produtividade, a flexibilidade e a racionalidade na lógica instrumental. 


\subsection{Os cursos sequenciais}

Os cursos sequenciais previstos na LDB e inspirados nos communiy colleges americanos,

[...] organizam-se conforme campos de saber, distintos das áreas de conhecimento - e suas áreas de aplicação -, a partir das quais se organiza a graduação [...], a qualificação de campos de saber encontra-se bastante fluida na normatização sobre os cursos sequenciais. Considera-se que estas podem estar contidas em uma das áreas fundamentais do conhecimento ou formar um campo multidisciplinar (IAMAMOTO, 2004, p. 54).

A legislação apresenta duas modalidades desses cursos superiores não graduados: de complementação de estudos - de destinação coletiva ou individual - e de formação específica. Os cursos sequenciais de complementação de estudos devem estar vinculados a um ou mais cursos da graduação, e os de destinação individual têm duração variada e são propostos pelos candidatos, enquanto os de destinação coletiva são definidos pela instituição quanto à oferta, carga horária e integralização.

A compreensão das entidades da categoria profissional sobre os cursos sequenciais de complementação de estudos é de que os mesmos podem significar um mecanismo de contribuição ao processo de formação continuada desde que sigam os critérios de:

a. viabilizarem-se a partir do projeto ético-político profissional;

b. possibilitar a qualificação da categoria profissional por meio desses cursos;

c. restringir a oferta de curso de complementação de estudos a graduandos e graduados em Serviço Social e outras áreas para garantir a interdisciplinaridade;

d. a oferta desses cursos para graduandos deve ser considerada como complementar e não integralizadora do curso no currículo (Relatório do Seminário Nacional da ABEPSS, 2000, p. 173-174).

Os cursos sequenciais superiores de formação específica compreendem 1.600 horas ou 400 dias letivos e são cursos de curta duração, vinculados à área do saber. Fornecem diplomas, embora não ofereçam grau e respondam à lógica mercantil de qualificar quadros técnico-instrumentais para o mercado, com salários menores que os correspondentes aos de cursos graduados.

A lógica perversa desses cursos sequenciais de formação específica se aplica às mais variadas situações: cria ilusões nas massas trabalhadoras quanto ao ingresso na universidade; porém, esse é realizado em curso de segunda linha, posto que os de 
primeira linha são destinados a uma elite; no mercado, abrem-se postos de trabalho sob denominação genérica. Permite que todos concorram em que os mais qualificados - graduados - tenham maior chance de adquirir a vaga, por um salário deteriorado, rebaixado pelos cursos de curta duração, além de quebrarem determinados cursos graduados de formação profissional, pois os de curta duração acabam sendo vendidos como seus substitutos.

A ABEPSS, no âmbito da formação profissional, a ENESSO, na esfera da organização estudantil, e o conjunto CFESS/CRESS no exercício profissional defendem e lutam pelo mesmo projeto de profissão, formação.

Isso fortalece o posicionamento político unitário em uma programática comum e articulada para o enfrentamento das questões que atingem o projeto profissional do Serviço Social brasileiro e de sua direção sociopolítica.

\subsection{Os Mestrados profissionalizantes}

Os mestrados profissionalizantes na lógica da LDB, regulamentados pela Portaria 080 de 16/1298, da Fundação Coordenação de Aperfeiçoamento de Pessoal de Ensino Superior (Capes); visam “a formação de profissionais pósgraduados para elaborar novas técnicas e processos”. Neste sentido, diferenciamse dos mestrados acadêmicos que "visam o aprofundamento de conhecimentos, ou técnicas de pesquisa científica, tecnológica ou artística”.

Sob a lógica de dar flexibilidade à educação, no neoliberalismo, os mestrados profissionalizantes vêm no sentido de: a) com maior agilidade, rapidez, menor custo, qualificar o corpo docente em 30\% do quadro de doutores e mestres exigidos pela LDB em detrimento da qualidade e natureza dos mestrados acadêmicos de formação de docentes, b) responder às exigências do mercado de trabalho mais hierarquizado para melhor qualificação na competitividade de postos de trabalho reduzidos diante da precariedade do trabalho e do desemprego; c) tendência gradativa de supressão dos mestrados lato sensu na pós-graduação, substituindo-os por mestrados profissionais, em detrimento da pesquisa e da qualidade acadêmica. O Encontro Nacional de Pós-Graduação realizado em dezembro de 2005, em Recife (PE) reafirmou a posição da ABEPSS contrária à implantação dos mestrados profissionalizantes. 


\subsection{O Ensino a Distância}

O Ensino a Distância (EaD) é um dos elementos chaves da contrarreforma do Ensino Superior no Brasil regulamentado pela LDB/1996 que segue o receituário do FMI e do Banco Mundial, a ser aplicado nos países de economia atrasada. A legislação a distância em seu artigo 80 prevê que “o poder público incentivará o desenvolvimento e a veiculação de programas de ensino a distância em todos os níveis e modalidades de ensino e de educação continuada”, e em 1998, o governo FHC regulamenta este artigo pelo decreto 2494/98. O incentivo da esfera estatal para os programas de ensino a distância prevê a abertura de 700 mil novas vagas, o que abre o caminho para a expansão da privatização, em uma diminuição gradativa do ensino presencial e a correspondente ampliação de cursos semipresenciais e de ensino a distância. A partir de 1995, apresenta-se o maior crescimento de ensino a distância da última década; de 200 mil estudantes no EaD, em 1990, aumentou para 1.137.908 em 2006, considerados os alunos de todas as modalidades de ensino a distância. Em relação aos cursos de graduação e pós-graduação, tem-se o dado de dez cursos de EaD no ano 2000, que em um período de quatro anos foi ampliado para 106 cursos com um crescimento de $1.000 \%$ em 2004. A crise da educação é parte da crise social resultante da exploração e do desemprego, em que a massificação do ensino, é parte constitutiva do capitalismo decadente pelo ensino privado.

Oficialmente estão credenciados 18 estados da Federação para a realização dos cursos de EaD, correspondendo a: Norte, 11.6644 alunos; Nordeste, 57.982 alunos; Centro-Oeste, 23.588; Sudeste, 16.387 alunos; Sul 52.856 alunos, totalizando 309.957 alunos, o que corresponde a um terço do total de alunos existentes nos cursos de educação a distância em todos os níveis.

O EaD é concebido para ser um ensino massivo, contraposto à universalização do ensino público, estatal e em todos os níveis. Prevê o número reduzido de tutores e técnicos na utilização desta força de trabalho em detrimento dos educadores presenciais, na lógica da flexibilização de direitos.

A Portaria de número 4059/2004 do Ministério da Educação e Cultura - MEC do governo Lula determina que "as universidades e institutos de ensino superior poderão introduzir até $20 \%$ de seus cursos à modalidade semipresencial” como parte dessa política. 
A escola, o processo educacional e as tecnologias devem ser analisadas no interior das relações econômicas e sociais presentes no capitalismo monopolista. A tecnologia e sua aplicação podem e devem ser utilizadas no processo educacional; no entanto, não pode ocorrer a substituição do ensino presencial pelo ensino virtual em nome da lucratividade, no interesse do capital.

As entidades da categoria ABEPSS, CFESS-CRESS e ENESSO pronunciaramse contrárias à implementação de cursos de graduação a distância, reafirmando: educação como direito, indissociabilidade entre ensino, pesquisa e extensão, processo formativo básico na perspectiva da totalidade e criticidade na apreensão da realidade social. Apresenta, na particularidade do curso de Serviço Social, a importância do ensino presencial em relação ao ensino do trabalho profissional (ou ensino da prática) em todas as fases do processo formativo, realização do estágio profissional supervisionado de modo presencial e com acompanhamento dos supervisores acadêmicos de campo, realização de pesquisa e investigação como princípio que perpassa toda formação profissional. Neste sentido, a implementação dos cursos de graduação a distância "se confronta radicalmente com os nossos compromissos e princípios e colidem com os conteúdos, habilidades e competências previstas nas diretrizes curriculares para os cursos de Serviço Social” (ABEPSS/ CFESS/ CRESS/ ENESSO, 2006).

Em 2010 as entidades da categoria iniciam uma grande campanha Educação não é fast-food, acompanhada de um documento que analisava porque Educação a distância é incompatível com a formação em Serviço Social. A campanha foi judicializada, portanto proibida de ser veiculada, como mais um instrumento autoritário do Governo federal em relação à livre expressão e manifestação. Em 2011, segundo dados do MEC, o Serviço Social é o terceiro curso no país a oferecer EaD, vindo atrás de Pedagogia e Administração, o que indubitavelmente corrói o ensino de qualidade, presencial, universal, por que lutamos.

\subsection{A formação profissional do Serviço Social no interior do processo de contrarreforma do Ensino Superior no Brasil}

A ampliação do ensino privado no país totaliza $82 \%$ dos cursos em detrimento de 18\% nas universidades públicas em 2012. O Sistema de abertura, credenciamento e avaliação dos cursos, embora definido pela Comissão de Especialistas da ABEPSS, com Serv. Soc. \& Saúde, Campinas, SP v. 11, n. 1 (13), p. 7-26 jan./ jun. 2012 ISSN 1676-6806 
parâmetros que se assentam nas diretrizes curriculares aprovadas em seus fóruns, sua aplicação segue a lógica instrumental, além de ser um instrumento extra universidade, incidindo sobre a autonomia e democracia universitárias. O Conselho Nacional da Educação aprovou as Diretrizes Curriculares suprimindo aspectos fundamentais que expressam um retalhamento do projeto de formação, em um primeiro momento decidindo pelo total de 2.700 horas para o curso. Após muita mobilização e pressão da ABEPSS, com apoio do conjunto CFESS/CRESS, da ENESSO, conjuntamente com as unidades de ensino nesta luta, conseguiu-se finalmente a aprovação das 3.000 horas defendidas pela categoria.

A ABEPSS se posicionou contrariamente ao conjunto de medidas da contrarreforma do Ensino Superior, com destaque, a saber: contra os cursos sequenciais para alunos não graduados, posto que abrem o caminho para a desprofissionalização na implantação de cursos técnicos e não de formação profissional; contra os mestrados profissionalizantes, posto que se pretende substituir os mestrados acadêmicos necessários à docência; contra o Ensino a Distância, por um ensino presencial de qualidade; contra a precarização do ensino e do trabalho que se amplia pela reestruturação produtiva e quebra de direitos educacionais.

Os rebatimentos da precarização do ensino e da mercantilização se materializam na alarmante expansão e hoje majoritária existência da rede privada de ensino com sistema de hora aula para o docente, sem a obrigatoriedade da pesquisa e da extensão que conformam a tríade do ensino superior; a extensão, quando surge, se faz de maneira "maquiada" afim de receber recursos da filantropia e se adequa em grande parte ao mercado; grande parte das unidades de ensino não dispõem de espaço físico e infraestrutura didático-pedagógica para o exercício da docência; classes beirando a 100 alunos bem superior ao previsto no projeto pedagógico; o pagamento hora-aula para o professor nas universidade privadas, não prevê o pagamento com o planejamento das atividades, estudo, orientações aos alunos, acompanhamento pedagógicos por período, correção de trabalhos. A Lei de Estágio aprovada em 2010, abre um flanco para a inserção de alunos desde o primeiro período no estágio, mas na realidade se trata de uma (de) formação profissional para substituir profissional por mão de obra-barata, sob a consigna de estágio.

O Sistema de Avaliação do Ensino Superior (SINAES) possui três instrumentos a saber: ENADE (avaliação externa dos estudantes a partir do Governo Lula, que corresponde ao "Provão" do Governo FHC), avaliação de cursos e avaliação Serv. Soc. \& Saúde, Campinas, SP v. 11, n. 1 (13), p. 7-26 jan./ jun. 2012 ISSN 1676-6806 
institucional. Até 2009 esses instrumentos tinham o peso proporcional de 35\% ENADE, 35\% Avaliação de Cursos e 30\% Avaliação Institucional. A Avaliação externa era realizada e caso a Unidade de Ensino tivesse avaliação superior a três, somente seria novamente avaliada por solicitação da unidade de ensino. A partir de 2010, para culpabilizar os estudantes que boicotaram o ENADE, por meio de deliberação de suas executivas de curso, no caso do Serviço Social ENESSO, ao zerarem as provas por não reconhecerem essa avaliação externa, o MEC passou a atribuir o peso de $70 \%$ para o ENADE, o que significa dizer que mesmo com a Avaliação Institucional e de Curso, a Unidade de Ensino passa a ter a nota dois, o que é considerado insuficiente. O MEC além de voltar a cada dois anos para avaliação interfere nos cursos punindo-os com redução do número de vagas em uma mediada coercitiva, punitiva, mais uma vez de ingerência na Unidade de Ensino.

\subsection{Lutas gerais da categoria dos assistentes sociais com o movimento da}

\section{Educação}

No plano imediato da política educacional, lutamos juntamente com o movimento da educação pelas bandeiras de lutas definidas coletivamente:

a. $10 \%$ para a educação, para que os 400 milhões que se destinam à filantropia sejam direcionados para o ensino público estatal;

b. pela autonomia da universidade em todos os seus aspectos: pela indissociabilidade entre ensino, pesquisa e extensão;

c. por uma universidade pública, laica, gratuita, universal, para que a produção do conhecimento esteja voltada para os interesses concretos postos pela realidade social;

d. que a universidade cumpra sua finalidade social; portanto, sua direção social deve se voltar para a grande massa de trabalhadores, democratizando o acesso e a permanência, e a luta para que o recurso público seja destinado à escola pública;

e. pela mudança na orientação das políticas de focalização de acesso;

f. para que a rubrica de assistência estudantil seja reinserida no orçamento objetivando assegurar material pedagógico, alimentação em restaurantes universitários, subsídios para transporte, moradia estudantil; 
g. por bolsas de Iniciação Científica (IC), como parte do trabalho acadêmico, para todos os estudantes que atenderem os requisitos democraticamente estabelecidos com ampla participação estudantil;

h. para que os aposentados sejam mantidos em folha de pagamentos do MEC e tenham assegurada a paridade com os ativos;

i. extinção das fundações privadas de apoio;

j. valorização da carreira docente e dos técnicos administrativos e realização de concursos públicos;

k. livre organização sindical; lutar para impedir que haja abertura da educação como área de investimento estrangeiro, combater as políticas de ajuste estrutural do Banco Mundial e do FMI;

l. pela cooperação solidária e não mercantil entre os povos.

A luta pelo ensino de qualidade na agenda do movimento da educação (estudantes, professores e funcionários) pressupõe a luta contra a contrarreforma do Ensino Superior em curso em nosso país. O XI CBAS em Fortaleza (2004) posicionouse contrariamente a esta contrarreforma em continuidade à luta de resistência contra 0 neoliberalismo reafirmada em todos os nossos fóruns de organização e deliberação.

Lutar por uma reforma do ensino superior progressiva pressupõe que se estabeleça:

a. garantia de ensino público universal como política e como direito;

b. estatização sem indenização de toda a rede particular de ensino sob o controle dos que nela estudam e trabalham;

c. constituição de um Sistema Único de Ensino, em que se exclui o ensino pago como condição para garantir o direito democrático de acesso ao ensino superior a todos;

d. defender com mobilização e organização as reivindicações estudantis e da educação contra a contrarreforma do Ensino Superior do governo,

e. combater, portanto, a ideia de uma educação determinada pelos interesses mercantilistas do empresariado da educação.

A educação é expressão das relações econômicas e sociais; portanto, em uma sociedade de classes, não há possibilidade de universalização das políticas, uma vez que a burguesia e o Estado a seu serviço não têm interesse em abrir a escola para todos, pois em sua essência necessita acumular capital e explorar força de trabalho. 
A burguesia nacional e o reformismo social-democrático subservientes ao imperialismo mostram-se incapazes para realizar as tarefas democráticas, que precisariam ser implementadas, pois essas não foram realizadas em países capitalistas de desenvolvimento tardio. É necessário, portanto, que se tenha uma posição histórica

[...] consequente, ou seja, proletária e revolucionária, fazer a defesa da solução das tarefas democráticas sob a estratégia da revolução social, que transformará a propriedade privada dos meios de produção em propriedade coletiva, somente o modo de produção baseado na propriedade e na distribuição coletiva colocará à disposição de todos a escola e o conhecimento (OLIVEIRA, 2004, p. 36).

\section{REFERÊNCIAS}

ABRAmides, M. B.C. O Projeto Ético-Político Profissional do Serviço Social Brasileiro. Tese de Doutorado, PUCSP, 2006.

ABRAMIDES, M. B.C. Contrarreforma do Ensino Superior sob a lógica neoliberal. Revista PUCViva-Faces da Educação-Reforma Universitária, ano 6, n 21, São Paulo, julho a setembro de 2004-ISNN-1806-3667.

CFESS, ABEPSS, ENESSO. Abaixo a Censura - Sobre a Incompatibilidade entre Serviço Social e Ensino a Distância. Brasília, 2011- site www.cfess.org.br. CHAUÍ, M. A Universidade Operacional: atual Reforma do Estado ameaça esvaziar a instituição universitária com uma lógica de mercado. São Paulo, FSP,09 de maio de 1999.

IAMAMOTO, M. V. Reforma do Ensino Superior e Serviço Social. Temporalis. ABEPSS, ano I, $n^{\circ} 1$, jan./ jun. de 2000.

NETTO, J. P. A Reforma do Estado e impactos no Ensino Superior, Revista ABEPSS, Temporalis I, Reforma do Ensino Superior e Serviço Social, ano I n 1, jan./ jun 2000. OLIVEIRA, E. M. Reforma da Educação no Governo PT/Lula. Revista PUCViva. Faces da Educação: Reforma Universitária, Ano 6, nº 21, jul./ set. 2004.

REVISTA PUCViva. Mercantilização do Ensino e Ensino à Distância. Ano 10, n ${ }^{\circ} 35$, mai./ago. 2009. São Paulo. ISSN 1806-3667 
Serv. Soc. \& Saúde, Campinas, SP v. 11, n. 1 (13), p. 7-26 jan./ jun. 2012 ISSN 1676-6806 